\title{
Experimental Study on the Durability of GFRP Materials
}

\author{
Liu Jianwei ${ }^{1, a}, Z_{\text {Zhou Shiming }}^{2, a}$, Peng Yiliang ${ }^{1, a}$, Sun Qing ${ }^{2, d^{*}}$ \\ ${ }^{1}$ Henan Electric Power Survey \& Design Institute, Zhengzhou 450007, China \\ 2Department of Civil Engineering, Xi'an Jiaotong University, Xi'an, 710049, China \\ aliujianwei-heny@powerchina.cn, bzsm.xpyxbd@stu.xjtu.edu.cn, \\ cpyl_ok@126.com, ${ }^{d *}$ sunq@mail.xjtu.edu.cn
}

\begin{abstract}
Keywords: Transmission pole and tower; Glass fiber reinforced polymer (GFRP); Durability; Xenon lamp aging; High and low temperature
\end{abstract}

\begin{abstract}
This paper studied the durability of Glass Fiber Reinforced Polymer (GFRP) in transmission pole and tower under the UV and adverse temperature environment. The results show that both UV and adverse temperature environment influence the performance of GFRP material, with its strength significantly reduced, and its elastic modulus increased, while the Poisson's ratio changed slightly. Xenon lamp aging affects the material properties of the specimens with protective coatings more slightly than those without any protective coatings. High temperature environment affects the material properties of specimens more obviously than low temperature environment does. Therefore, when designing the GFRP transmission pole and tower exposed in UV and adverse temperature environment long-term, designers should consider the negative impacts of the external environment, and take appropriate protective treatments.
\end{abstract}

\section{Introduction}

Pole and tower structure is an important support structure in the transmission and other infrastructure, whose structural properties directly affect the safety, economy and reliability of the transmission lines. The materials of transmission pole and tower widely applied internationally are wood, concrete or prestressed concrete, steel pipe concrete and steel, while the steel pole and tower is most widely used at present ${ }^{[1]}$. But traditional transmission pole and tower commonly have the disadvantages of heaviness, perishability, corrosion, craze and so on ${ }^{[2-5]}$. Besides, it is hard to transport and maintain. What's more, the transmission of steel pole and tower has faults of pollution flashover and windage yaw discharge etc.

Fiber Reinforced Polymer (FRP) is paid more and more attention in engineering field, as it has superiority of high strength, light weight, rust-resistant, workableness, designability, and good insulation. With the development of FRP technology and manufacture technics, it is possible to apply FRP pole and tower in transmission. The use of FRP can save amount of steels. And due to FRP's insulation, it is not only easy to solve windage yaw and pollution flashover incidents to improve the safe standard of transmission running, but also likely to reduce the size of tower head and the width of corridor. Moreover the FRP tower's specialty of portability and easiness to process may reduce its cost of transportation and assembly. Furthermore FRP material has the merits of corrosion resistance, bearing the high and low temperature, the high intensity, and little possibility to be stolen, so it can reduce maintenance cost to use FRP pole and tower. Meanwhile the color of FRP tower is adjustable; FRP material is nonpoisonous and can still be reused after being discarded, so the use of FRP can strengthen the environment friendliness.

In addition, with power transmission network construction scale expanding continually, the 
running and maintenance issues of transmission line structure will become increasingly prominent. At the same time the comprehensive cost-benefit analysis of the transmission structure will be taken seriously gradually. By analyzing comprehensive cost-benefit of pole and tower used different materials, the results show that annual average cost in life cycle of FRP pole and tower is the lowest. It demonstrates FRP pole and towers have good technical and economical efficiency.

The running environment of the transmission pole and tower is quite adverse, especially in the high temperature and high-cold area, so the thermo stability of resin material is important correspondingly. What's more, the resin substrate is easy to get aging under ultraviolet ray influence, and the aging wreck of transmission pole and tower can possibly cause power cut accident. All these are important factors which restrict the FRP pole and tower application.

According to the request of SG Corp. of China, and relying on the transmission project for \pm $660 \mathrm{kV}$ transmission pilot of the Yinchuan east convertor station $\sim$ Hongliugou Ground, the application research on FRP transmission pole and tower was made. This paper mainly studied the durability of FRP material in transmission pole and tower. The xenon lamp aging and the high and low temperature environmental test were conducted to study the durability of GFRP material, mainly the material performance under the ultraviolet ray aging and the adverse temperature environment, aiming to provide the basis and instruction for the GFRP electric transmission poles and towers project application.

\section{Test general situation}

\section{Material and specimens}

The material of specimen in the test is E-GFRP, and the specimens are made by the Anshan Yuanda Power Engineering Ltd., according to the relevant provisions in the "glass steel test methods" which recommended by the State Administration of Building Materials in China. The pattern of specimen is shown in Figure 1, the size is shown in Table 1, and the specimens are shown in Figure 2.

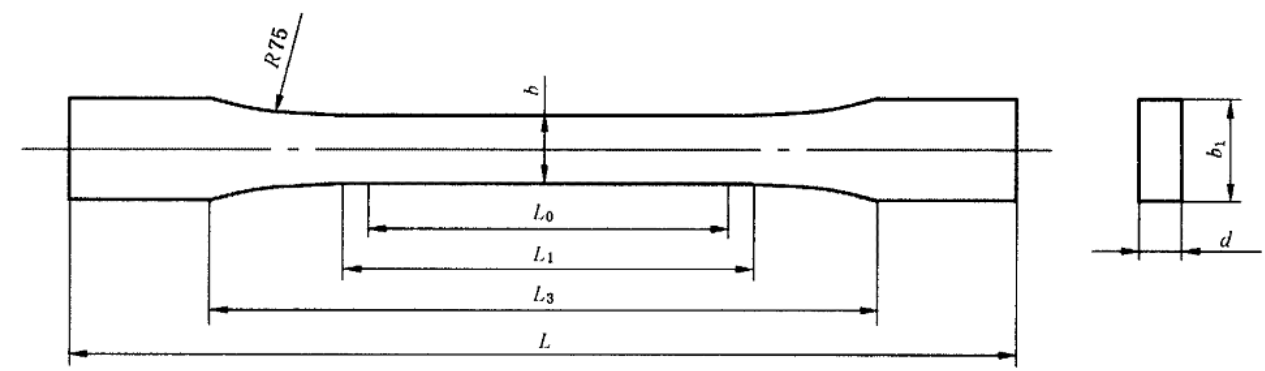

Fig. 1 the pattern of specimen

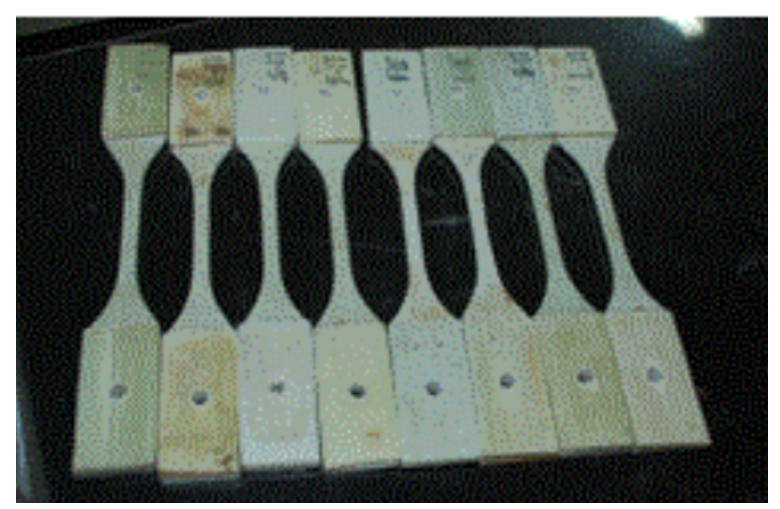

Fig.2 Specimen 
Tab.1 the sizes of specimens (Unit: $\mathrm{mm}$ )

\begin{tabular}{c|c|c|c|c|c|c|c}
\hline specification & $L$ & $L_{0}$ & $L_{1}$ & $L_{3}$ & $b$ & $b_{l}$ & $d$ \\
\hline E- FRP & 180 & 50 & 55 & 115 & 10 & 40 & 4 \\
\hline
\end{tabular}

\section{Methods and equipments of xenon lamp aging test}

A total of ten xenon lamp aging specimens are divided into two groups of five specimens, The specimens of one group have not any protective coatings (the group number is XD1), while the specimens of the other group have protective coatings on the surfaces (the group number is XD2). In order to compare, the mechanical properties of eight specimens without any aging treatment (the group number is JB) are tested specifically.

The type of the xenon lamp aging chamber is SN-900, with temperature changing range of RT40 ${ }^{\circ} \mathrm{C} \sim 70{ }^{\circ} \mathrm{C}\left( \pm 2{ }^{\circ} \mathrm{C}\right)$, humidity range of $85 \% \sim 90 \%( \pm 3 \% \mathrm{RH})$, and rainfall time range of $0 \sim 99$ minutes. The power of light - source- water-cooled xenon arc lamp is $6 \mathrm{KW}$, and the control system is high-precision temperature and humidity controller which is made in Japan. The test conditions of the test chamber is in terms of A cycle as far from "The Methods of Exposure to Light Sources in Plastic Laboratory(GB/T 16422.2-1999)", with the radiation degree of 500w/(m^2.nm)@340nm, continuous exposure time of $102 \mathrm{~min}$, black standard temperature of $(65 \pm 3){ }^{\circ} \mathrm{C}$, relative humidity of $(50 \pm 5) \% \mathrm{GH}$, illumination and spray of $18 \mathrm{~min}$, color filter of Boro, and the exposure time of 192h. The test chamber is shown in Figure 3.

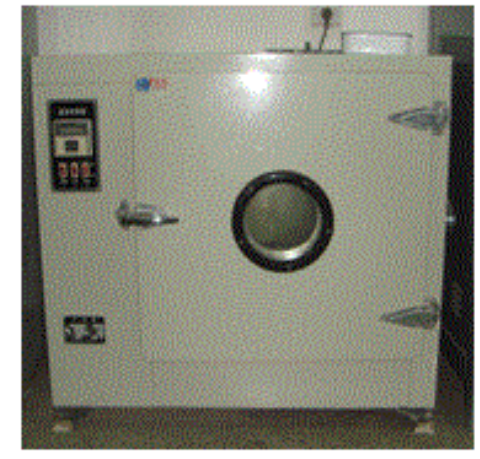

Fig.3 Xenon lamp aging chamber of SN-900

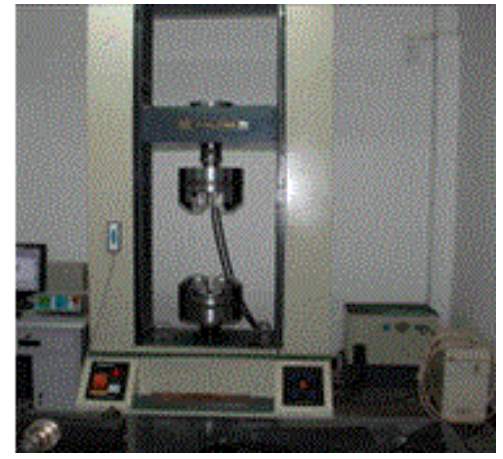

Fig.4 material tensile testing machine of LongHua of WDW-300D

The material performance of the aging specimens were tested with the tensile testing machine made by Shanghai Longhua, shown in Figure 4, whose type is WDW-300D and whose accuracy is up to level 0.5. In the tensile test the statistics of load and displacement etc. were recorded automatically. The type of the strain gauges used in both material elastic modulus test and Poisson ratio test is CML-1H produced by Beidaihe Electronic Instrument Plant in China, and the type of orthogonal strain flower is BE120-3BC produced by Zhonghang Electronic Measuring Instruments Co. Ltd. (ZEMIC). The vertical and horizontal strain of the specimens under different loads were tested with the strain flower, then the Passion rate can be calculated according to the ratio of the vertical and horizontal strain

\section{Methods and equipments of high and low temperature test}

There are six specimens in each group of high temperature test and low temperature test, which are numbered 1-1 1-6 and 2-1 2-6 respectively. The specimens whose number begins with 1 belong to low temperature test group, while the ones whose number begins with 2 belong to the other group. The specimens are shown in Figure 5. During the high and low temperature test, specimens were placed in constant temperature environment chamber, with the temperature $80^{\circ} \mathrm{C}$ in 
high temperature test and the temperature $-30{ }^{\circ} \mathrm{C}$ in the low temperature test. Then the tensile tests were carried out in this environment chamber to test the elastic modulus, Poisson's ratio, and nominal stress of materials in high and low temperature.

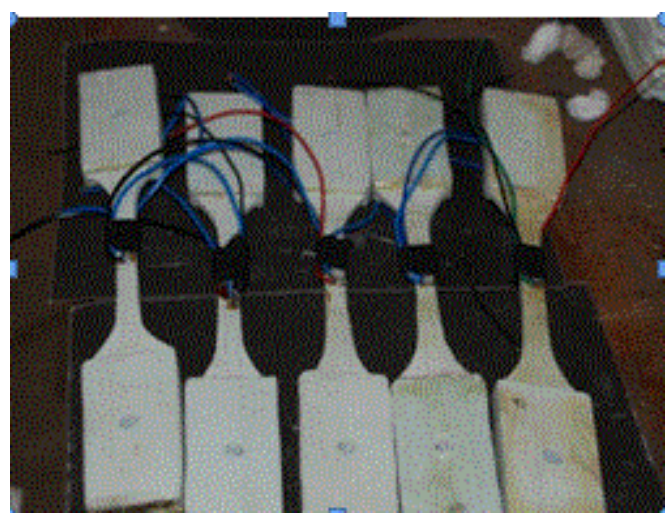

Fig.5 Specimens in high and low temperature test

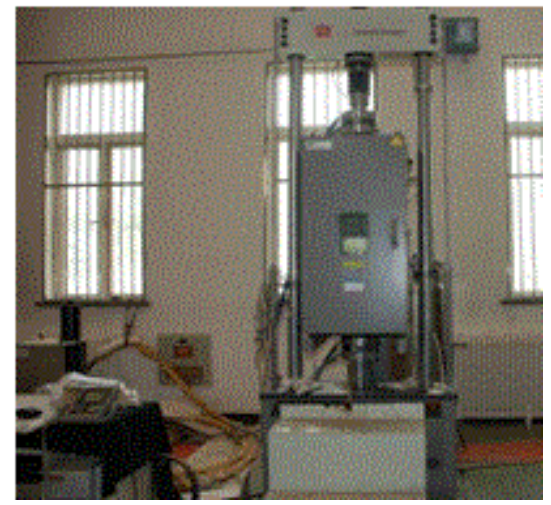

Fig.6 high and low temperature environmental chamber of MTS810

The type of the environmental chamber in high and low temperature environment test is MTS810, which is shown in Figure 6. And with the environmental chamber, the uniaxial tension test, tension-tension fatigue test and tension- compression fatigue test under temperature ranged from $-129{ }^{\circ} \mathrm{C}$ to $+540{ }^{\circ} \mathrm{C}$ can be carried out. Automatic control system with self-heating is used from room temperature to $+540{ }^{\circ} \mathrm{C}$, and Dewar with liquid nitrogen cooling system is used from room temperature to $-129{ }^{\circ} \mathrm{C}$. The type of the strain gauge used to test the elastic modulus and Poisson ratio is MTS810 system, and the type of orthogonal strain flower is BE120-3BC.

\section{Test results and analysis}

\section{results and analysis of Xenon lamp aging test}

In the ten data of the specimens in Xenon lamp aging test there were two pathological data from the specimens without protective coating, and one pathological data from the specimens with protective coating. Otherwise there were three pathological data from the specimens without aging treatment. All the pathological data were removed. A linear fitting to the data of each specimen was made to obtain the elastic modulus and Poisson's ratio. Then based on the fitting results the average strength, elastic modulus and Poisson's ratio of each group specimens were calculated. The test data and the analysis results are shown in Table 2-4, in which the failure nominal stress is the ratio of failure load detected in the test and the initial cross-sectional area of the specimen. The various mechanical properties curves of specimen JB-1s are shown in Figure 7-10, and the ones of specimen XD-1 are shown in Figure 11 and Figure 12, which correspondingly include Load-displacement (L-D) curve , Stress-displacement (Str-D)curve, Nominal stress-vertical strain(Nstr-Vs) curve, and Horizontal strain-vertical strain(Hs-Vs) curve. 


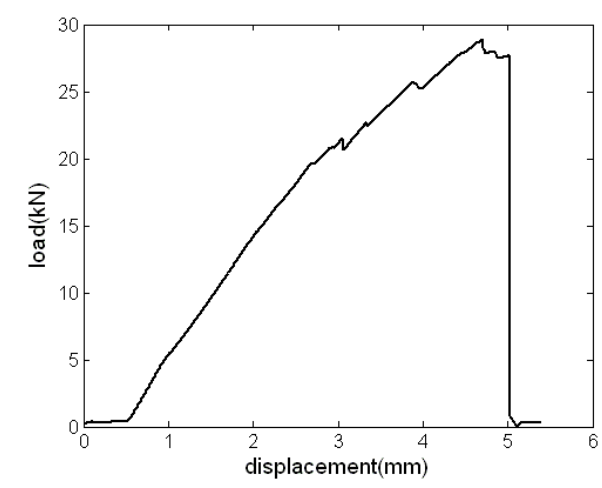

Fig.7 L-D curve of specimen JB-1

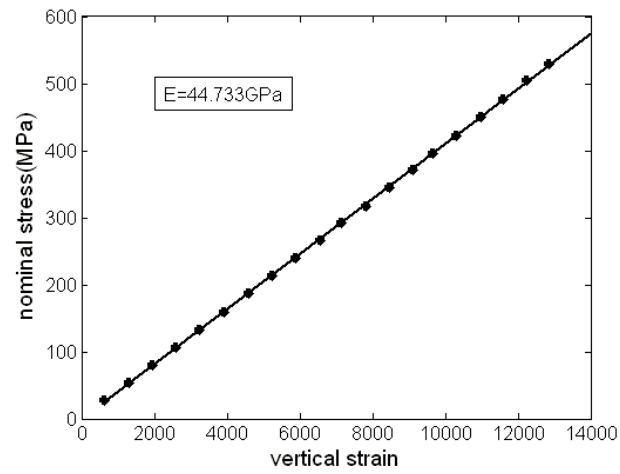

Fig.9 Nstr-Vs curve of specimen JB-1

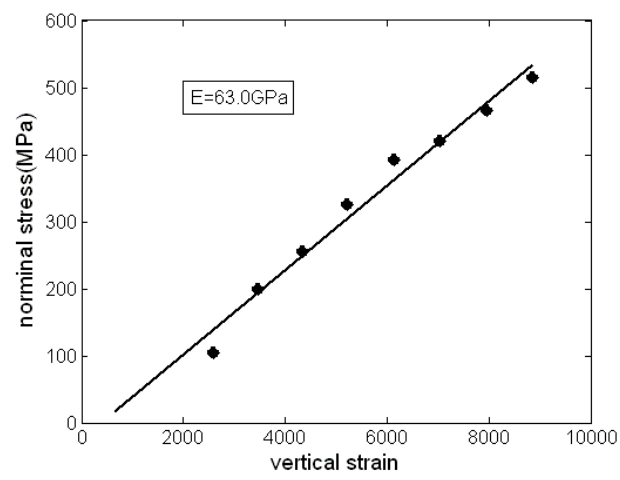

Fig.11 Nstr-Vs curve of specimen XD-1

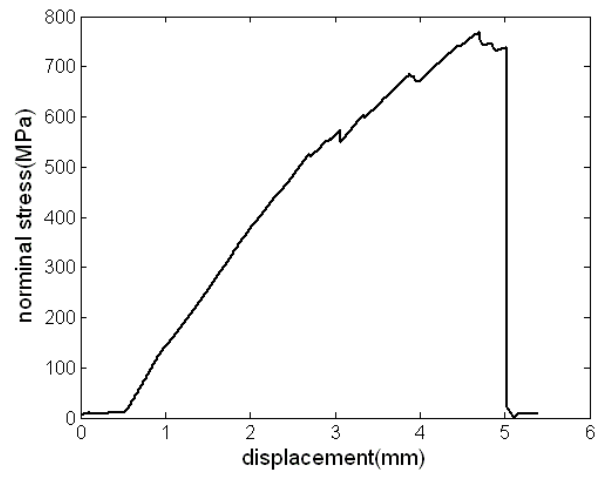

Fig.8 Str-D curve of specimen JB-1

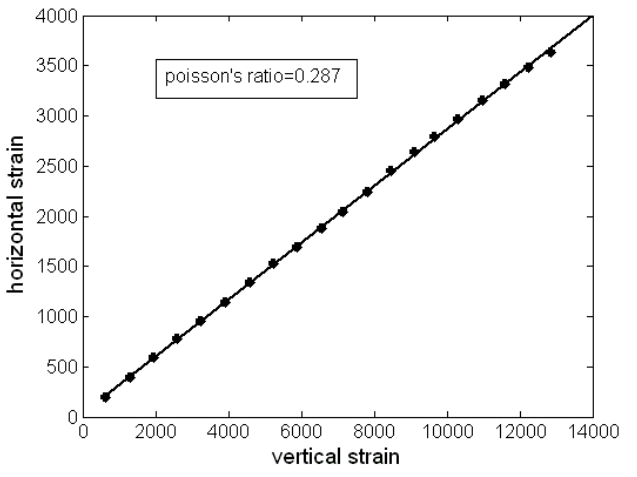

Fig.10 Hs-Vs curve of specimen JB-1

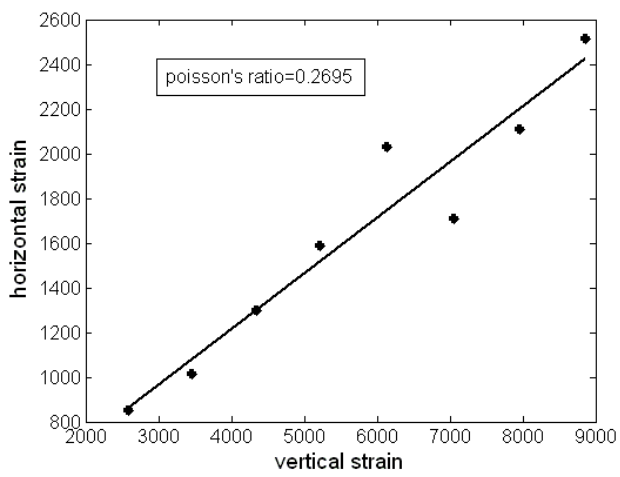

Fig.12 Hs-Vs curve of specimen XD-1

Tab.2 the tensile test results of specimens with Xenon lamp aging test

\begin{tabular}{l|c|c|c|c|c|c|c}
\hline Identifier & XD1-1 & XD1-2 & XD1-3 & XD2-1 & XD2-2 & XD2-3 & XD2-4 \\
\hline Section width $(\mathrm{mm})$ & 6.78 & 7.48 & 7.30 & 8.30 & 7.40 & 7.36 & 7.16 \\
\hline Section thickness $(\mathrm{mm})$ & 4.32 & 4.30 & 4.50 & 4.22 & 4.42 & 4.20 & 4.12 \\
\hline Nominal stress $(\mathrm{MPa})$ & 514.09 & 430.73 & 506.61 & 637.28 & 701.568 & 538.87 & 573.36 \\
\hline Poisson' s ratio & 0.2695 & 0.2569 & 0.2991 & 0.3991 & 0.2644 & 0.2552 & 0.3263 \\
\hline E $(\mathrm{GPa})$ & 63.0 & 50.3 & 78.6 & 61.9 & 61.6 & 79.5 & 68.0 \\
\hline
\end{tabular}

Tab.3 the tensile test results of specimens without Xenon lamp aging test

\begin{tabular}{c|c|c|c|c|c}
\hline Identifier & JB-1 & JB-3 & JB-4 & JB-6 & JB-8 \\
\hline E (Gpa) & 44.733 & 46.579 & 45.179 & 45.649 & 43.386 \\
\hline Poisson's s ratio & 0.287 & 0.299 & 0.296 & 0.2929 & 0.258 \\
\hline
\end{tabular}


Tab.4 the comparison of each test group

\begin{tabular}{c|c|c|c}
\hline Group & no protective coating & protective coating & no ageing treatment \\
\hline Average nominal stress $(\mathrm{MPa})$ & 483.81 & 612.77 & 843.5 \\
\hline Average modulus of elasticity $(\mathrm{GPa})$ & 63.97 & 67.75 & 45.105 \\
\hline Average Poisson's s ratio & 0.2752 & 0.2963 & 0.287 \\
\hline
\end{tabular}

The results show that the strength of specimen decreased obviously after xenon lamp aging test. After the exposure period of eight days, the average strength of specimens without protective coating decreased by 42.6 percent, while the average strength of specimens with protective coating decreased by 27.5 percent. Therefore, after the same aging test, the strength of the specimens with protective coating decreased smaller than the ones without protective coating, and the former is 1.27 times of the latter. This shows that the protective effect is very remarkable with protective coating, so it is suggested that in practical project the pole and tower should be made a protective coating.

After xenon lamp aging test the elastic modulus of the specimens increases obviously, while the Poisson's ratio changes slightly. This shows that UV will decline the ultimate strain of the material. So it is suggested that when designing GFRP transmission pole and tower which will exposure to UV for a long time, the negative effect of UV should be considered.

\section{results and analysis of high and low temperature environment test}

The failure loads of the specimens in high and low temperature environment were tested by tensile test. The typical failure mode of the specimens is shown in Figure 13, the typical load-displacement curves are shown in Figure 14 and Figure 15, and the fitting curves of elastic modulus are shown in Figure 16 respectively.
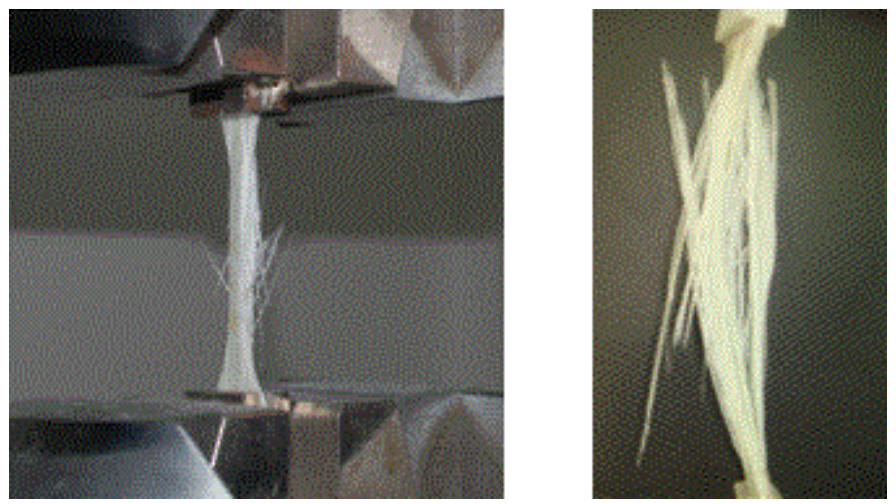

Fig.13 Typical failure mode of specimen

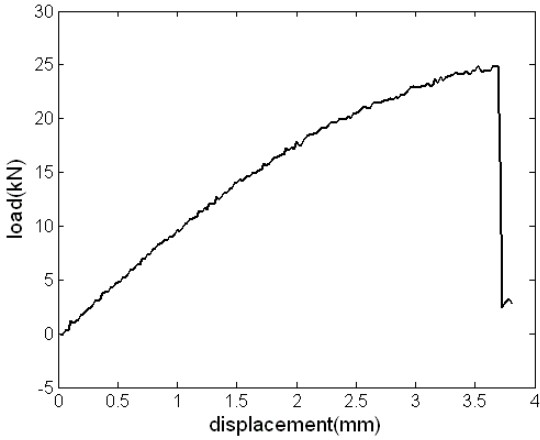

Fig.14 L-D curve of specimen in high temperature test

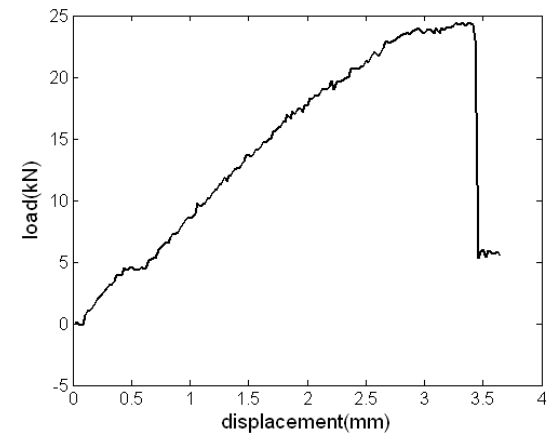

Fig.15 L-D curve of specimen in low temperature test 

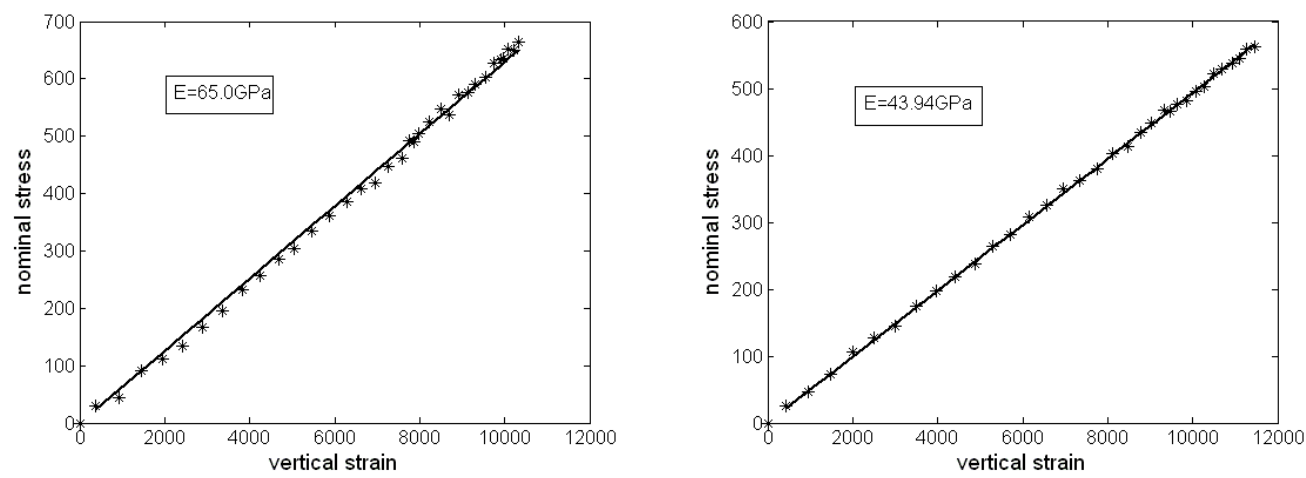

Fig.16 Nstr-Vs curve of specimen in low temperature test

Tab. 5 the primary data of each specimen

\begin{tabular}{c|c|c|c|c|c|c}
\hline Identifi er & $1-1$ & $1-2$ & $1-3$ & $1-4$ & $1-5$ & $1-6$ \\
\hline Section area $\left(\mathrm{mm}^{2}\right)$ & 40.00 & 37.14 & 40.20 & 44.18 & 38.13 & 42.56 \\
\hline Failure load $(\mathrm{KN})$ & 31.00 & 27.67 & 26.85 & 30.82 & 26.70 & 33.5 \\
\hline Identifi er & $2-1$ & $2-2$ & $2-3$ & $2-4$ & $2-5$ & $2-6$ \\
\hline Section area $\left(\mathrm{mm}^{2}\right)$ & 39.60 & 37.25 & 36.48 & 34.24 & 38.44 & 41.92 \\
\hline Failure load $(\mathrm{KN})$ & 27.05 & 26.44 & 22.82 & 20.40 & 25.16 & 28.44 \\
\hline
\end{tabular}

Tab.6 the test results of specimen in low and high temperature Environment

\begin{tabular}{c|c|c|c|c|c|c}
\hline Identifier & $1-1$ & $1-2$ & $1-3$ & $1-4$ & $1-5$ & $1-6$ \\
\hline Nominal stress (MPa) & 775.00 & 744.92 & 667.91 & 697.59 & 700.27 & 787.12 \\
\hline E (Gpa) & 65.00 & 43.94 & 49.17 & 56.78 & 53.05 & 46.56 \\
\hline Poisson's ratio & 0.31156 & 0.31539 & 0.28204 & 0.29014 & 0.24886 & 0.23358 \\
\hline Identifier & $2-1$ & $2-2$ & $2-3$ & $2-4$ & $2-5$ & $2-6$ \\
\hline Nominal stress (MPa) & 683.08 & 709.82 & 625.55 & 595.79 & 654.55 & 678.44 \\
\hline E (Gpa) & 40.05 & 52.41 & 60.36 & 59.81 & 59.78 & 58.20 \\
\hline Poisson's satio & 0.28737 & 0.33601 & 0.33395 & 0.29339 & 0.32150 & 0.42042 \\
\hline
\end{tabular}

Tab.7 the comparison of low temperature and high temperature

\begin{tabular}{|c|c|c|}
\hline Group & low temperature & high temperature \\
\hline Average nominal stress $(\mathrm{MPa})$ & 728.8 & 657.9 \\
\hline Average modulus of elasticity ( $\mathrm{GPa})$ & 52.42 & 54.17 \\
\hline Average Poisson's ratio & 0.28 & 0.33 \\
\hline
\end{tabular}

The primary data are shown in Table 5. The elastic modulus and Passion rate of each specimen in the test are got through linear fitting. Then by analyzing these data, the strength, elastic modulus and Poisson rate of each specimen and each group are got, which are shown in Table 6 and Table 7.

Through the above data and comparing the tensile test data of non-aging specimen, the conclusion can be got that low temperature environment and high temperature environment both make negative impacts on the bearing capacity of the material. After the aging test of low 
temperature and high temperature, the average ultimate stress declined by 13.6 percent and 22.0 percent respectively, and the high temperature makes a more negative impact on the properties of the material. The specimens didn't display clear plastic phase during the loading process. Namely, the fracture is brittle fracture. Comparing the data of the specimens without any aging test, the modulus all increased in low and high temperature environment. This shows that extreme (or negative) temperature environment will decline the ultimate strain of the material. So it is suggested that when designing GFRP transmission pole and tower which will exposure to low or high temperature environment for a long time, the negative effect of low and high temperature environment should be considered.

\section{Conclusions}

This paper mainly studied the durability of GFRP in transmission pole and tower. The environmental factors included mainly UV aging and adverse temperature, which were considered through Xenon lamp aging test and high and low temperature environment test. The following conclusions can be drawn from this study:

1) The UV and high and low temperature environment all affect the material properties of GFRP pole and tower, with the strength decreasing obviously, the modulus increasing slightly, and Poisson rate changing insidiously. This shows that the aging environment outside will decline the ultimate strain of the material, so it is suggested that when designing GFRP transmission pole and tower exposure to UV and low or high temperature for a long time, the negative effect of the adverse environment outside should be considered.

2) After Xenon lamp aging test of the same conditions, the strength of specimen with protective coating declines less than that without protective coating. The protective effect is very remarkable with protective coating, so it is suggested that in practical project the pole and tower should be made a protective coating.

3) High and low temperature environment both make adverse effects on the strength of the material, and the high temperature makes a more negative impact on the properties of the material. Typical failure mode of specimen is brittle. So in practical project the adverse effects of high temperature to GFRP transmission pole and tower should be considered and the appropriate protective treatment should be taken.

\section{References}

[1] Richard Stewart. Pultruded poles carry power[J]. Reinforced plastic, 2003(1): 20-24

[2] Sherif Ibrahim, Dimos Polyzois, Sherif K. Hassan. Development of glass fiber reinforced plastic poles for transmission and distribution lines[J]. Canadian Journal of Civil Engineering. 2000, 27(5): 850-858

[3] Bo Chen. Fiber Reinforced Plastics, 36-42 (1996), In Chinese

[4] Zhongqi Sun, Chen Guanfu, Liyan Huang. Power System and Clean Energy, Vol.24, 23-26(2008), In Chinese

[5] Kaiquan Xia, Tech Fiber \& Application, Vol. 30, 19-23(2005), In Chinese

[6] Donghong Fang, Jianping Han, Cuiling Cao. Glass Fiber, 31-35 (2008), In Chinese 